\title{
Computação Desplugada no Ensino Fundamental I: Um Mapeamento Sistemático de Literatura
}

\author{
Elaine Cristina Grebogy ${ }^{1}$, Icleia Santos ${ }^{1}$, Marcos Alexandre Castilho ${ }^{1}$ \\ ${ }^{1}$ Departamento de Informática - Universidade Federal do Paraná (UFPR) \\ Curitiba - PR - Brasil \\ \{elaine.grebogy, icleia.santos\}@ufpr.br, marcos@c3sl.ufpr.br
}

\begin{abstract}
This study presents a survey of initiatives that promote Computational Thinking in an unplugged manner -without the use of technological and/or digital artifacts-in Elementary School 1. It provides an overview of the studies, addresses the different types of activities used, analyzes the processes evaluations by which they are submitted, their main objectives, the researchers' motivation for this option of approach, the duration of the initiatives and whether they are supported by any learning theory.
\end{abstract}

Resumo: Este estudo apresenta um levantamento das iniciativas que promovem o Pensamento Computacional de maneira desplugada -sem o uso de artefatos tecnológicos e/ou digitais- no Ensino Fundamental 1. Traz um panorama geral dos estudos, aborda os diferentes tipos de atividades utilizadas, analisa os processos avaliativos pelos quais são submetidos, seus principais objetivos, a motivação dos pesquisadores por essa opção de abordagem, a duração das iniciativas e se estão apoiadas em alguma teoria de aprendizagem.

\section{Introdução}

A prática de habilidades relacionadas ao Pensamento Computacional tem demonstrado constante evolução no Ensino Fundamental e tem sido apontado pelos Pesquisadores como um meio, para promover nos estudantes, a criticidade e a capacidade de resolver problemas. Apesar de ser um termo recente na literatura, o Pensamento Computacional (PC) vem sendo considerado como um dos "pilares fundamentais do intelecto humano, junto com a leitura, a escrita e a aritmética" (SBC, 2018, p. 5) pois, descreve, explica, modela e apoia a compreensão do universo e seus sistemas complexos. Refere-se à capacidade de compreender, definir, modelar, comparar, solucionar, automatizar e analisar problemas (e soluções) de forma metódica e sistemática, por meio da construção de algoritmos (SBC, 2018.)

Diferentes Autores (Wing ,2006; Grover \& Pea ,2013; Brackmann et al. 2017; Mioto et al. 2019) afirmam que há uma crescente ênfase na importância do PC como uma habilidade fundamental para o cidadão do século XXI e como consequência são notórios os esforços e o interesse pela pesquisa e desenvolvimento de recursos tecnológicos voltados a apoiar os processos de ensino-aprendizagem do PC.

$\mathrm{O}$ exercício do PC permite construir processos educativos que possibilitem ao educando o protagonismo, trabalho em colaboração e o desenvolvimento da criatividade, o que também vai ao encontro do Plano Nacional de Educação - PNE (Brasil, 2001) e à Base Nacional Comum Curricular - BNCC (2018), os quais destacam a importância desse conhecimento para que os estudantes sejam capazes de solucionar desafios cotidianos e consequentemente, obter melhor aprendizagem. 
O estudo de Zanetti et al., (2016) e Rodrigues et al., (2018), apresentam o resultado da computação desplugada com um enfoque no ensino de programação, sem um critério específico de nível de escolaridade. Em Avila et al., (2017) e Araujo et al., (2016) a abordagem do PC se concentra na avaliação em contextos educacionais diferenciados. Carvalho et al., (2017), analisam o uso de técnicas (objetos de aprendizagem) que apoiam o PC em diferentes contextos, utilizando-se de bases nacionais. Em Souza \& Nunes, (2019), Ortiz \& Pereira, (2018) e Bordini et al., (2017), apresenta-se um panorama atual do ensino do PC em níveis de educação variados, sem se aprofundar em abordagens específicas

Este estudo se diferencia dos demais ao investigar as práticas de Computação Desplugada (CD) que acontecem exclusivamente nos anos iniciais do Ensino Fundamental (EF1) e está organizado da seguinte maneira: A Seção 2 apresenta uma breve introdução ao Pensamento Computacional. Na Seção 3, apresenta-se o percurso metodológico deste estudo. Na Seção 4 são descritos os resultados. Concluindo, na Seção 5 são apresentadas as considerações finais seguidas das Referências.

\section{Pensamento Computacional}

O Pensamento Computacional (PC), do inglês, Computational Thinking (CT) está associado ao processo cognitivo para resolução de problemas, design de sistemas e compreensão do comportamento humano, norteados por conceitos fundamentais da Ciência da Computação (Wing, 2006). O ato de pensar computacionalmente apresenta-se como uma competência que, de acordo com Cavalcante et al., (2016), consiste no conjunto de habilidades e atitudes vinculadas a realização de uma ação, cujo principal objetivo é o da resolução de problemas, sendo assim, relevante para todas as pessoas.

A British Broadcasting Corporation (BBC) Learning, (2020) resumiu os elementos do PC, denominando-os "Quatro Pilares do Pensamento Computacional", sendo eles: Decomposição, Reconhecimento de Padrões, Abstração e Algoritmos.

A prática do PC, segundo (Brackman, 2017), envolve identificar um problema complexo e quebrá-lo em pedaços menores e mais fáceis de gerenciar (Decomposição). Cada um desses problemas menores pode ser analisado individualmente com maior profundidade, identificando problemas parecidos que já foram solucionados anteriormente (Reconhecimento de Padrões), focando apenas nos detalhes que são importantes, enquanto informações irrelevantes são ignoradas (Abstração). Por último, passos ou regras simples podem ser criados para resolver cada um dos subproblemas encontrados (Algoritmos).

No século XXI o conhecimento em computação é tão importante e necessário quanto o ensino de outras disciplinas como ciências, português ou matemática. Para Blikstein (2008), a sociedade atual exige muito mais do que ler, escrever, adição e subtração. Sendo assim, um número crescente de países tem desenvolvido currículos de referência para guiar o ensino de PC na Educação Básica, convergindo em termos de conceitos e técnicas fundamentais e sequenciamento de estágios educacionais.

No Brasil, a Sociedade Brasileira da Computação - SBC, por entender que os conceitos da Computação já devam ser ensinados a partir da Educação Básica, incentiva ações que possam promover a introdução da Computação nas escolas, apresentando diretrizes referentes ao ensino de computação na Educação Básica, que incluem o Pensamento Computacional (SBC, 2018) além do mundo e a cultura digital. 
No contexto educacional brasileiro, o PC foi inserido na Base Nacional Comum Curricular como uma das competências atreladas à área de Matemática e suas Tecnologias, assim como o raciocínio lógico (BRASIL, 2018).

\subsection{Computação Desplugada}

Atualmente, diversas estratégias instrucionais são adotadas para desenvolver o PC na educação básica como parte do ensino de computação. Embora a estratégia mais comum se utilize de computadores e outros artefatos tecnológicos, há a opção de utilização de atividades de forma desconectada, ou seja, sem uso de dispositivos digitais, as quais incluem, por exemplo o uso de jogos de tabuleiro ou cartas, ou atividades cinestésicas, usadas para representar e entender conceitos de PC, como algoritmos (Wangenheim et al., 2020).

Um dos principais exemplos de atividades desplugadas, são as desenvolvidas por Tim Bell, Ian H. Witten e Mike Fellows, no livro "Computer Science Unplugged" (Bell; Witten; Fellows, 2011). Além do livro, há o projeto CS Unplugged ${ }^{1}$ que disponibiliza materiais didáticos gratuitos (como planos de aula, vídeos e livros de atividades) para o ensino de conceitos da Ciência da Computação por meio de jogos e materiais de baixo custo, sem usar softwares ou hardwares.

A Computação Desplugada é utilizada no ensino de fundamentos da Ciência da Computação, permitindo que o estudante aprenda de maneira concreta e divertida, sem a necessidade de aparatos tecnológicos. Ao considerar o Censo Escolar da Educação Básica de 2019 (INEP, 2019), constata-se que não há um número expressivo de escolas públicas que dispõe de computadores para uso por parte dos alunos. Os computadores de mesa aparecem em menos de $35 \%$ delas e os portáteis em apenas $20 \%$. O documento traz ainda, a informação de que apenas $61,5 \%$ das escolas públicas oferecem aos seus discentes acesso à internet. Sendo assim, a opção pela CD permite levar o conhecimento sobre Ciência da Computação a lugares em que os computadores e suas tecnologias ainda não são realidade (Santos et al., 2016).

O documento "Referenciais de Formação em Educação" (SBC 2017, p.7), cita como habilidades relacionadas à computação e ao PC para o EF: "Representar em experiências concretas as principais abstrações para descrever dados: registros, listas e grafos."; "Identificar as principais abstrações para construir processos: escolha, composição e repetição, simulando e definindo algoritmos simples que representem situações do cotidiano infantil."; "Utilizar linguagem lúdica visual para representar algoritmos."; e "Compreender a técnica de decompor um problema para solucioná-lo.".

As escolas de Ensino Fundamental - EF são veículos relevantes para implantação do uso do PC, no sentido de incentivar habilidades para desenvolvimento pleno e efetivo do raciocínio logico-dedutível, principalmente nos primeiros anos escolares (Campos et al., 2014). Ao considerar as fases de desenvolvimento de Piaget, ${ }^{2}$ os alunos do Ensino Fundamental I estão em uma fase de transição do seu desenvolvimento, encontram-se no estágio pré-operatório, e operatório concreto, etapa em que estão obtendo alicerces cognitivos importantes para a construção do pensamento formal. Neste sentido o processo de ensino-aprendizagem é proposto do concreto ao abstrato, aproximando tanto a

\footnotetext{
${ }^{1}$ https://www.csunplugged.org/en/

${ }^{2}$ Piaget dividiu o desenvolvimento humano em quatro fases: Sensório-motor (0-2 anos), Pré-operatório (2-7 anos), Operações Concretas (7-12 anos) e Operações Formais (a partir de 12 anos) (Nogueira \& Leal, 2015, p. 141).
} 
construção do pensamento formal quanto a aprendizagem de conceitos e habilidades relacionadas ao PC.

\section{Percurso Metodológico}

Para este estudo, utilizou-se a Metodologia de Brereton (Brereton et al., 2007), cujo protocolo segue as etapas: a) especificação das questões de pesquisa, b) definição dos termos de busca, c) escolha das bases de dados, d) critérios de inclusão e de exclusão e e) síntese dos trabalhos selecionados.

Para análise dos dados, foi adotada a metodologia de análise de conteúdo (Bardin, 2011) em três fases. A primeira com a pré-análise dos estudos retornados, por meio de uma leitura rápida (scanning), com ênfase nos resumos, nas seções de resultados e/ou conclusões. A segunda com a aplicação dos critérios de inclusão - CI e critérios de exclusão - CE e seleção da amostra final. A terceira etapa, com o tratamento, inferência e interpretação dos dados, com a leitura na íntegra, de todos os trabalhos.

No intuito de se obter uma visão abrangente das pesquisas efetivadas no Ensino Fundamental 1 (EF1), este estudo apresenta um levantamento das iniciativas que promovem o Pensamento Computacional de maneira desplugada, ou seja, sem o uso de artefatos tecnológicos e/ou digitais. Com isso, pretende-se responder à principal questão desta pesquisa: "Como as práticas de CD vêm sendo trabalhada especificamente no EF1, para o desenvolvimento do Pensamento Computacional ?" Com base nessa questão principal, elaborou-se as seguintes questões de pesquisa:

QP1- Qual o panorama atual das pesquisas envolvendo a CD no EF1? Com o objetivo de analisar o número de artigos publicados por ano e em quais periódicos/conferências o tema tem predominância. Essa questão poderá indicar se há tendência de crescimento de ações relacionadas ao PC desplugado no EF1.

QP2- Essas iniciativas aconteceram em paralelo às aulas regulares? Buscando observar se o trabalhado foi realizado durante o período regular de aulas ou em oficinas e atividades extraclasse em contraturno. Isso permite inferir como PC ocupa o espaço das aulas.

QP3- Que tipo de atividades foram utilizadas? Para observar se foram replicadas (e.g. atividades do livro CS Unplugged, Code Org.) ou adaptadas e recriadas. Esta QP pretende apontar caminhos para se incluir a prática da abordagem no EF1.

QP4 - Essas práticas se apoiam em alguma teoria de aprendizagem? Para entender se há alguma teoria que embasa essas práticas, o que poderá apoiar teoricamente a inserção da metodologia na faixa etária pesquisada.

QP5 - As intervenções foram avaliadas? De que forma? Para entender como foram analisados os resultados dessas iniciativas, se por meio de observação, questionários ou entrevistas, se foram avaliadas as próprias atividades propostas pela pesquisa, com pré e pós testes, com um único teste, ou serão avaliados resultados em atividades externas.

QP6- Qual o tempo de duração das iniciativas? Para entender se há uma continuidade nas práticas, ou tratam-se de iniciativas isoladas.

QP7- O que motivou os Autores a optarem pela abordagem desplugada? Para entender os fatores que impactam na decisão de se trabalhar com essa abordagem. 
QP8- Quais os principais objetivos dos estudos e quais habilidades pretende-se estimular nos alunos? Para entender o que os autores buscaram estimular com as práticas de CD além do PC.

A partir das questões de pesquisa, foi elaborada a string de busca: ("Pensamento Computacional" OR "Computational Thinking") de maneira genérica, para se obter o maior número de trabalhos possíveis, visto que, ao se inserir termos como "Ensino Fundamental" e "Computação Desplugada" associados a string pesquisada, não houveram retornos significativos de publicações. A não inclusão na busca do termo Ensino Fundamental se justifica ainda, por se tratar de uma subdivisão especifica do sistema de ensino brasileiro.

A busca foi realizada nas principais bases de dados científicas e repositórios digitais on-line, como: ACM Digital Library, EI Compendex, IEEE Xplore, ISI Web of Science, Science Direct, Scopus, Springer Link, Scielo, Portal de periódicos da Capes, BDTD - Biblioteca Digital Brasileira de Teses e Dissertações, além dos Anais de eventos do Congresso da Sociedade Brasileira de Computação. (WIE, WEI, SBIE, Workshops do CBIE, Workshop de Informática na Escola), indexados na base da CEIE - Comissão Especial de Informática na Educação da SBC

Para compor este mapeamento os estudos analisados foram submetidos a Critérios de Inclusão (CI) e Critérios de Exclusão (CE), conforme Quadro 01:

Quadro 1 - Critérios de Inclusão e Exclusão de trabalhos.

\begin{tabular}{|l|c|l|}
\hline \multicolumn{1}{|c|}{ Critério } & ID & \multicolumn{1}{c|}{ Descrição } \\
\hline \multirow{4}{*}{ Inclusão } & I1 & $\begin{array}{l}\text { Trabalhos que abordam o PC de maneira Desplugada no Ensino } \\
\text { Fundamental 1, como Artigos completos, Teses, Dissertações e TCC }\end{array}$ \\
\hline \multirow{5}{*}{ Exclusão } & E1 & $\begin{array}{l}\text { Trabalhos que abordam o PC no Ensino Fundamental 1 e 2 simultaneamente, } \\
\text { Ensino Fundamental 2, Ensino Médio e Superior. }\end{array}$ \\
\cline { 2 - 3 } & E2 & Trabalhos duplicados (sendo considerado apenas o mais atual) \\
\cline { 2 - 3 } & E3 & Trabalhos não acessíveis de forma gratuita \\
\cline { 2 - 3 } & E4 & Trabalhos que abordem a CD em conjunto com outra abordagem plugada \\
\cline { 2 - 3 } & E5 & Trabalhos com foco no professor e não no aluno \\
\cline { 2 - 3 } & E6 & $\begin{array}{l}\text { Trabalhos no formato de Revisão Sistemática de Literatura, Mapeamento } \\
\text { Sistemático de Literaturas e conceituais sobre o tema. }\end{array}$ \\
\hline
\end{tabular}

Após as buscas nas bases de dados, houve retorno de 2.355 trabalhos ${ }^{4}$ dos quais, foram selecionados $764 \mathrm{em}$ um primeiro filtro, considerando àqueles relacionados ao EF. Á estes, foram aplicados manualmente os CI e CE por meio de uma leitura rápida (scanning), com ênfase nos resumos, nas seções de resultados e/ou conclusões, o que resultou na seleção de 132 trabalhos. Com a leitura na íntegra dos 132 trabalhos, e após a aplicação dos CI e CE chegou-se à amostra final de 17 estudos que compõem este mapeamento, organizados em uma tabela ${ }^{5}$ que sintetiza as informações dos estudos selecionados, com seu respectivo ID.

A pesquisa foi realizada entre os meses de abril e agosto de 2020 e a seleção dos trabalhos nas bases ocorreu no mês de abril de 2020. O retorno das informações nas bases

\footnotetext{
${ }^{4}$ https://drive.google.com/file/d/1MIKw6C5BEd_rsaZDNiWBQ5UBMMhd6wJS/view?usp=sharing

${ }^{5}$ https://drive.google.com/file/d/19Wx8ICKwU2uHVG4DHwaTQ5qRMo2cMQ9v/view?usp=sharing
} 
pesquisadas é apresentado na tabela 01 , ressaltando que só foram elencadas as bases onde se puderam incluir algum trabalho.

Tabela 1 - Retorno das Informações nas Bases Pesquisadas com aplicação dos Cl e CE

\begin{tabular}{lcc}
\hline Bases de Pesquisa & Total de retornos & Trabalhos analisados \\
\hline Workshop de Informática na Escola (WIE) & 34 & 7 \\
Congresso Brasileiro de Informática na Educação (CBIE) & 19 & 3 \\
Simpósio Brasileiro de Informática na Educação (SBIE) & 15 & 2 \\
Scopus Search & 41 & 1 \\
Workshop sobre Educação em computação (WEI) & 12 & 2 \\
Revista Novas Tecnologia na Educação - RENOTE & 3 & 1 \\
Scielo & 8 & 1 \\
\hline TOTAL & 132 & 17 \\
\hline
\end{tabular}

\section{Análise dos resultados}

Em atendimento a QP1, este mapeamento traz um panorama atual das pesquisas envolvendo a CD no EF1. Ao analisar a quantidade de trabalhos publicados por ano, fica evidente a evolução de estudos conforme mostra a figura 01 , ressaltando que no último ano concentram-se mais de $41 \%$ deles.

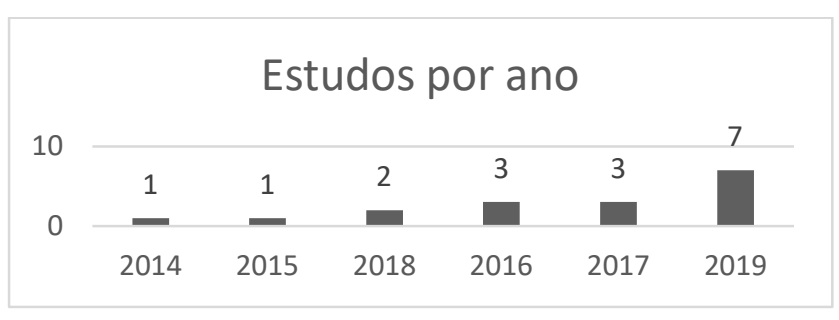

Figura 1 - Estudos por ano no EF1

Em atendimento às QP2 e QP3 buscou-se investigar se as iniciativas de promoção do PC por meio de atividades desplugadas aconteceram em paralelo às aulas regulares, em oficinas e atividades extraclasse ou em contraturno e ainda, entender o tipo de atividade utilizadas nestas práticas.

A maioria dos estudos 9/17 não trazem a informação de como as aulas aconteceram, porém, quando este aspecto é omitido, pode-se inferir que as práticas aconteceram em paralelo as aulas regulares, visto que os Autores não se preocuparam em deixar claro no estudo o local e o período das intervenções. Houveram quatro estudos $[4,8,9,14]$ em que se relatam a aplicação em turno regular, ou seja, paralelo às aulas, um caso [2] em que foram aplicadas atividades desplugadas em uma disciplina própria do PC em uma escola particular, outro em oficina extraclasse [1]. Em [3] os autores aplicaram as intervenções em três ambientes diferentes: uma escola pública, um curso de verão e em oficinas, e em [13] não houve aplicação prática, apenas uma proposta de intervenção.

Sendo assim, ao considerar que as práticas acontecem em sua maioria paralelo às aulas regulares, evidencia-se a necessidade de se associar os conceitos relacionados ao PC a disciplinas do currículo.

Em relação aos tipos de atividades, foram estabelecidas 4 categorias para agrupálas: i) jogos e atividades em papel, ii) jogos e atividades com materiais concretos, iii) 
Jogos e atividades motoras e iv) jogos matemáticos. Quanto a autoria das mesmas, apenas 2 estudos [6,7] relatam aplicação sem adaptações, os demais, criaram, recriaram ou adaptaram suas propostas de acordo com os objetivos dos estudos. Percebe-se que a principal inspiração para criação ou adaptação de atividades desplugadas foi o livro C.S. Unplugged (Bell et al., 2011)

Tabela 2- Descrição das atividades

\begin{tabular}{|c|c|c|}
\hline Descrição da atividade e exemplos & Inspiração para criação & Estudos relacionados \\
\hline $\begin{array}{l}\text { Jogos e atividades em papel (mapa com menor caminho, } \\
\text { números binários, colorindo com números, batalha naval, } \\
\text { métodos de ordenação, histórias em quadrinhos, algoritmos, } \\
\text { decomposição da Turma da Mônica, mapa da Turma da } \\
\text { Mônica, tetris, instruções e bugs). }\end{array}$ & $\begin{array}{l}\text { Problema do caminho mínimo, } \\
\text { C.S. Unplugged, Pensamento } \\
\text { Computacional Brasil. }\end{array}$ & {$[2,6,7,8,9,10,11,14]$} \\
\hline $\begin{array}{l}\text { Jogos e atividades com materiais concretos (jogos de } \\
\text { tabuleiros, cartas, jogo cara a cara, algoritmos em blocos) }\end{array}$ & $\begin{array}{l}\text { Scratch, C. S. Unplugged, } \\
\text { Code. Org. e Estrela. }\end{array}$ & {$[2,3,4,10,12,14]$} \\
\hline Jogos e atividades motoras (tabuleiro vivo, dinâmicas) & $\begin{array}{l}\text { OBI - Olimpíada Brasileira de } \\
\text { Informática, C. S. Unplugged. }\end{array}$ & {$[4,5,6,10,16]$} \\
\hline Jogos matemáticos & Não especificados. & {$[13,15,17]$} \\
\hline
\end{tabular}

Pela necessidade de adaptação das atividades utilizadas, percebe-se a necessidade de maiores opções de atividades desplugadas para o EF1.

Para responder a QP4, foram analisadas se a práticas de CD estão apoiadas em alguma teoria de aprendizagem. Apenas 03/17 estudos traziam essa informação. Em [8] os autores mencionam apoiar-se no construtivismo de Jean Piaget, ${ }^{7}$ no construcionismo de Papert $^{8}$, e no método desenvolvido por Polya ${ }^{9}$ acerca da resolução de problemas. Em [13] menciona-se o construtivismo cognitivo de Jean Piaget, a aprendizagem assistida sugerida por Vygotsky ${ }^{10}$ e a aprendizagem ativa ${ }^{11}$. A aprendizagem colaborativa foi a base teórica de [16].

Percebe-se que 2/3 trazem como aporte teórico para suas práticas $o$ Construtuvismo cognitivo de Jean Piaget. O Autor buscou mostrar que o conhecimento evolui progressivamente através de estruturas de raciocínio que substituem umas às outras por meio de estágios de desenvolvimento.

\footnotetext{
7 A teoria denominada epistemologia genética, foi definida pelo próprio Piaget (1974, p. 20) como o "estudo da passagem dos estados inferiores do conhecimento aos estados mais complexos ou rigorosos".

8 O construcionismo de Seymour Papert, (2008) traz reflexões sobre o uso de tecnologia como ferramenta mediadora na produção do conhecimento. Papert introduziu a tecnologia como ferramenta modificadora de relações de aprendizagem. O Construcionismo é uma reconstrução teórica a partir dos estudos desenvolvidos acerca do construtivismo de Piaget.

9 O método de resolução de problemas do matemático Polya (1995) apresenta quatro passos para facilitar a resolução de uma dada questão, que são (I) compreender o problema; (II) estabelecer um plano; (III) executar o plano e (IV) retrospecto.

10 A aprendizagem assistida sugerida por Vygotsky, conhecida ainda como socioconstrutivismo ou sociointeracionismo (Vygotsky, 1980), pressupõe que os estudantes desenvolvem habilidades de pensamento de alto nível por meio do desenvolvimento gradual e das interações socias entre os indivíduos. De acordo com o autor, essas interações constituem uma maneira eficaz de desenvolver habilidades e estratégias, habilidades estas que os alunos não conseguiriam alcançar sem o auxílio de um adulto ou de colegas. Este nível de desenvolvimento, denominado, zona de desenvolvimento proximal (ZDP) é estabelecido pela diferença entre a capacidade de resolver problemas sem ajuda e a capacidade de resolvê-los com a orientação de uma pessoa mais experiente.

11 A aprendizagem ativa destaca que os estudantes devem participar ativamente do processo de aprendizagem. Embora não exista uma definição precisa para este método, (Bonwell \& Eison, 1991) sua aplicação está relacionada com a adoção das seguintes estratégias: não tornar os alunos meros ouvintes (eles devem ser os protagonistas no respectivo processo de aprendizagem); dar menos ênfase a transmissão de informação e mais ênfase ao desenvolvimento de habilidades; envolver os estudantes em atividades de discussão, análise, síntese e avaliação; realçar a reflexão dos estudantes sobre suas atitudes. As estratégias consideradas para a inclusão da aprendizagem ativa incluem: (i) o trabalho conjunto, onde os alunos ajudam a responder as perguntas uns dos outros; (ii) a designação de estudantes para apresentar suas soluções para a turma. Estas estratégias vão de encontro também às adotadas na aprendizagem colaborativa.
} 
Percebe-se nas teorias apresentadas a importância dada a autonomia do aluno para que de fato ocorra seu desenvolvimento cognitivo. Destaca-se assim, a necessidade de usar atividades e materiais que favoreçam o interesse e motivem o estudante a buscar estratégias e soluções que contribuam no processo de aprimoramento das habilidades relacionadas ao PC.

Em atendimento a QP5, buscou-se investigar os processos avaliativos pelos quais as práticas de $\mathrm{CD}$ foram submetidas. Para melhor compreensão, as avaliações foram categorizadas em: a) questionários ou entrevistas, b) Avaliação com pré e pós teste, c) Observação por parte dos pesquisadores na realização das atividades propostas pela pesquisa ou do artefato final, d) Avaliação com um único teste ao final da intervenção, e) Não avaliados. A tabela 04 traz os resultados obtidos.

Tabela 3- Processos avaliativos

\begin{tabular}{cc}
\hline Processo avaliativo & Estudos relacionados \\
\hline Questionário $/$ & {$[3,6,17]$} \\
Entrevistas & {$[6,7,9,10,15,16]$} \\
Pré e pós teste & {$[2,4,5,8,14,17]$} \\
Observação & {$[1,8,11,12]$} \\
Teste final & {$[13]$} \\
Não avaliados &
\end{tabular}

Percebe-se a utilização de instrumentos de avaliação qualitativos e quantitativos, porém não há uma padronização de avaliações. Foi possível identificar que diversos estudos não reportam de forma explícita um fundamento teórico para suportar os instrumentos de avaliação e o processo avaliativo como um todo. Não há um consenso ou consolidação de um determinado método de avaliação, o que sugere a implementação de ações nesse sentido.

Para responder a QP6, este estudo fez um levantamento do tempo de duração das iniciativas de promoção do PC por meio da CD. Como não há uma padronização desse tempo (em horas aulas, em número de aulas ou encontros, em números de atividades) estabeleceu-se categorias que englobam tempo em horas/aulas e em número de encontros, conforme tabela 05:

Tabela 4- Duração das intervenções

\begin{tabular}{lc}
\hline \multicolumn{1}{c}{ Período de duração das intervenções } & $\begin{array}{c}\text { Estudos } \\
\text { relacionados }\end{array}$ \\
\hline Até 03 atividades ou 04 horas/aulas & {$[2,4,7,14]$} \\
De 04 a 06 atividades ou de 05 a 8 horas/aula & {$[5,6,9,10,11]$} \\
De 07 a 09 atividades ou de 09 a 12 horas/aula & {$[1,3,12]$} \\
Superiores a 10 atividades ou 13 horas aulas & {$[8,16]$} \\
Não especificados & {$[13,15,17]$} \\
\hline
\end{tabular}

Percebe-se que a maioria dos estudos se referem a iniciativas de curta duração, as quais não se relacionam com uma continuidade, com exceção de [8], em que a Autora trabalhou com a mesma turma durante 02 anos seguidos, e em [16] com duração de 11 meses, ou 60 horas/aula. A ausência de um componente curricular que favoreça a 
continuidade de ações nesse sentido, pode ser um dos fatores que implicam na descontinuidade da prática.

Em atendimento a QP7, buscou-se interpretar nos estudos selecionados, as motivações que levaram os autores a optarem pela abordagem desplugada, conforme ilustra a figura 02 :

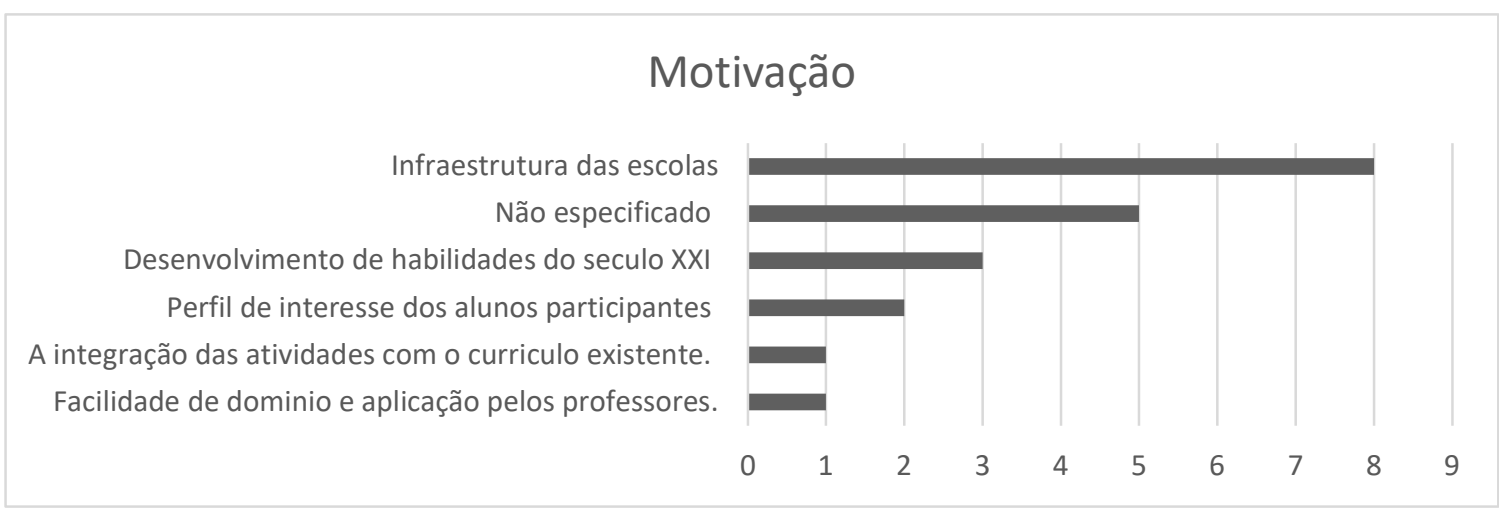

Figura 2- Motivação pela opção de Computação Desplugada

Percebe-se que a principal motivação foi a infraestrutura das escolas, que não possuíam um laboratório de informática ou acesso a computadores e dispositivos móveis $[1,3,4,5,6,11,12,13]$, por essa razão a CD foi a alternativa para tornar possível o acesso de todos, aos conceitos da computação independente da infraestrutura.

O desenvolvimento das habilidades necessárias aos cidadãos do século XXI, como trabalho colaborativo, resolução de problemas, habilidades comunicativas, criativas e pensamento crítico, também foram citados [8,16,17]. Destaca-se em [8] a importância de o aluno atuar sobre o computador e não somente utilizar os recursos previamente disponíveis no equipamento.

O perfil de interesse do público participante $[1,12]$ foram fatores que impactaram na escolha da metodologia desplugada. A facilidade de aplicação e domínio dos conteúdos propostos por parte dos professores [13] que nesta fase da educação brasileiraEF1-são responsáveis por ministrar a maioria das disciplinas e promover sua integração com conteúdos curriculares, também foram citados como fatores que contribuíram com a opção dessa abordagem.

As justificativas apresentadas demonstram que, a opção da $\mathrm{CD}$ não está relacionada apenas a falta de recursos digitais. Um importante apelo à abordagem nesta fase de educação, associa-se a oportunidade de exploração de materiais concretos para potencializar a construção do conhecimento em conformidade com a fase de transição do desenvolvimento - entre o estágio pré-operatório, e operatório concreto- em que os alunos do EF1 se encontram.

Em atendimento a QP8, foram sintetizados os principais objetivos dos estudos selecionados para este mapeamento e as habilidades relacionadas. $\mathrm{O}$ desenvolvimento de habilidades relacionadas ao Pensamento Computacional $[1,4,5,6,7,8,10,11,12,14,15,17]$ foi o principal objetivo de $70 \%$ dos estudos, como já era esperado. Dentre estas habilidades pode-se citar: Algoritmos, abstração, decomposição, reconhecimento de padrões, generalização, avaliação, coleta, representação e análise de dados). Os estudos 
[6,17] destacam ainda, as habilidades do século XXI, como pensamento crítico, habilidades criativas, colaborativas e comunicativas.

O raciocínio logico $[2,5,8]$ foi citado como principal objetivo em $17 \%$ dos estudos. Ainda como objetivo principal, em [13] destaca-se: exercitar habilidades matemáticas por meio de atividades desplugadas; em [3] ensinar conceitos de programação; em [9] o ensino de conceitos de computação e; em [16] importância da colaboração, permitindo o desenvolvimento de habilidades sociais, cognitivas e do pensamento computacional.

\section{Considerações finais.}

Com base nas análises foi possível entender como as práticas de $\mathrm{CD}$ vêm sendo trabalhadas especificamente no EF1 para o desenvolvimento do PC. A tendência de crescimento nas pesquisas demonstra a pertinência de estudos nesta faixa etária, onde se formam importantes bases para aquisição de habilidades futuras.

A CD proporciona o ensino de conceitos computacionais que desviam de barreiras de infraestrutura ou formação específica, de modo a redemocratizar o ensino do PC. No entanto, a falta de um componente curricular específico de computação no EF1, faz com que as iniciativas sejam promovidas de maneira transversal à outras disciplinas, o que pode comprometer a continuidade de ações.

As análises sugerem uma carência de material desplugado específico ao EF1, fase em que são tão oportunas atividades com materiais concretos e lúdicos para que os estudantes possam compreender conceitos ao manipular objetos e interagir utilizando seus sentidos.

O fato de a maioria dos estudos não estar associados a uma teoria de aprendizagem e se referir a iniciativas de curta duração que não proporcionam uma continuidade na aplicação, podem prejudicar o desenvolvimento efetivo do PC. Sendo assim, como trabalho futuro, sugere-se a criação de uma metodologia de ensino do PC para o EF1, com a abordagem desplugada, que possibilite sua aplicação de maneira contínua, elevando o grau de complexidade dos conceitos envolvidos, sustentada por uma teoria de aprendizagem e que estabeleça critérios claros para sua avaliação.

\section{Referências}

Araujo, A. L., Andrade, W., \& Guerrero, D. (2016). Um Mapeamento Sistemático sobre a Avaliação do Pensamento Computacional no Brasil. Anais Dos Workshops Do V Congresso Brasileiro de Informática Na Educação (CBIE 2016), 1(Cbie), 1147. https://doi.org/10.5753/cbie.wcbie.2016.1147

Avila, C., Cavalheiro, S., Bordini, A., \& Marques, M. (2017). O Pensamento Computacional por meio da Robótica no Ensino Básico - Uma Revisão Sistemática. Cbie, 82. https://doi.org/10.5753/cbie.sbie.2017.82

Bardin, L. (2011). Análise de Conteúdo (Edições 70 (ed.)).

Bell, T., Witten, I. H., \& Fellows, M. (2011). Computer Science Unplugged: Ensinando Ciência da Computação sem o uso do computador. Computer Science Unplugged (csunplugged.org).

Blikstein, P. (2008). O pensamento computacional e a reinvenção do computador na educação. 
http://www.blikstein.com/paulo/documents/online/ol_pensamento_computacional. html

Bonwell, C., \& Eison, J. (1991). Active Learning: Creating Excitement in the Classroom. ASHE-ERIC Higher Education Reports, Washington, D.C.

Bordini, A., Avila, C., Marques, M., Foss, L., \& Cavalheiro, S. (2017). Pensamento Computacional nos Ensinos Fundamental e Médio: uma revisão sistemática. Anais Do XXVIII Simpósio Brasileiro de Informática Na Educação (SBIE 2017),

Brackmann, C., Boucinha, R. M., Román-González, M., Barone, D. A. C., \& Casali, A. (2017). Pensamento Computacional Desplugado: Ensino e Avaliação na Educação Primária Espanhola. Anais Dos Workshops Do VI Congresso Brasileiro de Informática Na Educação (CBIE 2017).

Brasil. (2001). Plano Nacional de Educação - PNE - Lei Federal n. ${ }^{\circ}$ 10.172, de 9/01/2001., (2001).

Brasil. (2018). Base Nacional Comum Curricular- BNCC. In: MEC Ministério da Educação, 600. https://doi.org/10.1017/CBO9781107415324.004

Brereton, P., Kitchenham, B. A., Budgen, D., Turner, M., \& Khalil, M. (2007). Lessons from applying the systematic literature review process within the software engineering domain. Journal of Systems and Software, 80(4), 571-583.

British Broadcasting Corporation (BBC) Learning. (2020). Introduction to computational thinking. https://www.bbc.co.uk/bitesize/guides/zp92mp3/revision/1

Campos, G. M. de, Cavalheiro, S., Foss, L., Pernas, A. M., Piana, C. F. de B., Aguiar, M., Bois, A. Du, \& Reiser, R. (2014). Organização de Informações via Pensamento Computacional: Relato de Atividade Aplicada no Ensino Fundamental. Anais Do XX Workshop de Informática Na Escola (WIE 2014), 1(Cbie), 390. https://doi.org/10.5753/cbie.wie.2014.390

Carvalho, J., Netto, J. F., \& Almeida, T. (2017). Revisão Sistemática de Literatura sobre Pensamento Computacional por Meio de Objetos de Aprendizagem. Cbie, 223. https://doi.org/10.5753/cbie.sbie.2017.223

Cavalcante, A., Costa, L. D. S., \& Araujo, A. L. (2016). Um Estudo de Caso Sobre Competências do Pensamento Computacional Desenvolvidas na Programação em Blocos no Code.Org. Anais Dos Workshops Do V Congresso Brasileiro de

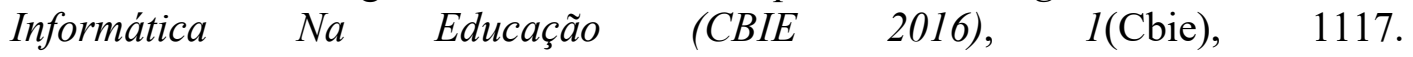
https://doi.org/10.5753/cbie.wcbie.2016.1117

INEP. (2019). Censo da Educação Básica 2019: Resumo Técnico. In Instituto Nacional de Estudos e Pesquisas Educacionais Anísio Teixeira.

Mioto, F., Petri, G., Gresse von Wangenheim, C., Ferreti Borgatto, A., \& Martins Pacheco, L. H. (2019). bASES21 - Um Modelo para a Autoavaliação de Habilidades do Século XXI no Contexto do Ensino de Computação na Educação Básica. Revista Brasileira de Informática Na Educação, 27(01), 26. https://doi.org/10.5753/rbie.2019.27.01.26

Nogueira, M. O. G., \& Leal, D. (2015). Teorias da Aprendizagem um encontro entre pensamentos filosófico, pedagógico e psicológico (2nd ed.). InterSaberes. 
Ortiz, J. D. S. B., \& Pereira, R. (2018). Um Mapeamento Sistemático Sobre as Iniciativas para Promover o Pensamento Computacional. Anais Do XXIX Simpósio Brasileiro de Informática Na Educação (SBIE 2018), l(Cbie), 1093. https://doi.org/10.5753/cbie.sbie.2018.1093

Papert, S. (2008). A Máquina das Crianças - Repensando a Escola na Era da Informátca. Artmed.

Piaget, J. (1974). A epistemologia genética e a pesquisa psicológica. Freitas Basto.

Polya, G. (1995). A arte de resolver problemas. Editora Interciência.

Rodrigues, S., Aranha, E., \& Silva, T. R. (2018). Computação Desplugada no Ensino de Programação: Uma Revisão Sistemática da Literatura. Anais Do XXIX Simpósio Brasileiro de Informática Na Educação (SBIE 2018), 1(Cbie), 417. https://doi.org/10.5753/cbie.sbie.2018.417

Santos, E. R. dos, Soares, G., Bianco, G. D., Filho, J. B. da R., \& Lahm, R. A. (2016). Estímulo ao Pensamento Computacional a partir da Computação Desplugada: uma proposta para Educação Infantil. Revista Latinoamericana de Tecnología Educativa (RELATEC), 15(3), 141-154. https://doi.org/10.17398/1695

SBC. (2017). Referenciais de Formação em Computação : Educação Básica (Issue 051). Sociedade Brasileira de Computação.

SBC. (2018). Diretrizes para ensino de Computação na Educação Básica - Ensino de Computação na Educação Básica. In Diretrizes para ensino de Computação na Educação Básica. Sociedade Brasileira de Computação. http://www.sbc.org.br/documentos-da-sbc/send/131-curriculos-de-referencia/1177diretrizes-para-ensino-de-computacao-na-educacao-basica

Souza, F. F. de, \& Nunes, M. A. S. N. (2019). Práticas e resultados obtidos na aplicação do Pensamento Computacional Desplugado no ensino básico: Um Mapeamento Sistemático. Cbie, 289. https://doi.org/10.5753/cbie.sbie.2019.289

Vygotsky, L. S. (1980). Mind in society: The development of higher psychological processes. Harvard university press.

Wangenheim, C. G. Von, Medeiros, G. A. e S. de, Filho, R. M., Petri, G., Pinheiro, F. da C., Ferreira, M. N. F., \& Hauck, J. C. R. (2020). Desenvolvimento e Avaliação de um Jogo de Tabuleiro para Ensinar o Conceito de Algoritmos na Educação Básica. Revista Brasileira de Informática Na Educação, 27(03), 310. https://doi.org/10.5753/rbie.2019.27.03.310

Wing, J. (2006). Computational Thinking. Communications of the ACM, 1-5. https://doi.org/0001-0782/06/0300

Zanetti, H., Borges, M., \& Ricarte, I. (2016). Pensamento Computacional no Ensino de Programação: Uma Revisão Sistemática da Literatura Brasileira. Anais Do XXVII Simpósio Brasileiro de Informática Na Educação (SBIE 2016), 1(Cbie), 21. https://doi.org/10.5753/cbie.sbie.2016.21 